\title{
Pure Laparoscopic Anatomic Resection of the Segment 8 Dorsal Area Using the Dorsal Approach of the Right Hepatic Vein
}

\author{
Santiago López-Ben, $\mathrm{MD}^{1,2,3}$, Maria Teresa Albiol, $\mathrm{MD}^{1,2}$, Laia Falgueras, $\mathrm{MD}^{1}$, Celia Caula, $\mathrm{MD}^{1}$, \\ Francesc Collado-Roura, $\mathrm{MD}^{1}$, Ernest Castro, $\mathrm{MD}^{1,2,3}$, Margarida Casellas, $\mathrm{MD}^{1,2}$, Jorge Garcia-Adamez, $\mathrm{MD}^{1}$, \\ and Antoni Codina-Cazador, MD, PhD ${ }^{1,2,3}$ \\ ${ }^{1}$ General Surgery-HPB Unit, Hospital Universitari de Girona Doctor Josep Trueta, Girona, Spain; ${ }^{2}$ Biomedical Research \\ Institute of Girona (IDIBGI), Girona, Spain; ${ }^{3}$ Department of Medical Sciences, Faculty of Medicine, University of Girona, \\ Girona, Spain
}

\begin{abstract}
Background. Anatomical resection of segment 8 (s8) is a challenging procedure. $\mathrm{S} 8$ can be subdivided into two areas: ventral $(\mathrm{s} 8 \mathrm{v})$ and dorsal (s8d). In the last years, different approaches for performing laparoscopic resection of s8 or any of its subsegments have been described, i.e. the hilar extrafascial approach, transfissural approach for $\mathrm{s} 8 \mathrm{v}$, transparenchymal approach for s8d, and the intrahepatic Glissonean approach. We recently described the dorsal approach of the right hepatic vein (RHV) for anatomical segment 7 resection. This video report describes the approach to a dorsal s8 pedicle using the RHV dorsal approach.

Methods. A 50-year-old woman with a history of morbid obesity and sleep apnea was diagnosed after episodes of hematochezia sigmoid cancer and a 2-cm liver metastases in the s8d, according to vascular reconstruction (Cella Medical Solutions, Murcia, Spain). The surgical technique started with mobilization of the right liver until the root of the RHV was identified and exposed in a craniocaudal fashion and until the s8d Glissonean pedicle was identified
\end{abstract}

and clamped. Indocyanine green counterstaining depicted an intersegmental plane between the s8d and segment 5 and $\mathrm{s} 8 \mathrm{v}$. Transection continued until the anterior fissural vein was exposed at its root, as a landmark of the medial plane. Results. Operative time lasted $265 \mathrm{~min}$. Transection was carried out using the intermittent Pringle maneuver over a period of $81 \mathrm{~min}$. Estimated blood loss was $252 \mathrm{cc}$. There were no postoperative complications and the patient was discharged on postoperative day 2 .

Conclusions. In some cases, the RHV dorsal approach can be used as the landmark for the s8d Glissonean pedicle, allowing anatomical resection of this particular area.

DISCLOSURES Santiago López-Ben has received grants from Olympus, Baxter, and Integra. Maria Teresa Albiol, Laia Falgueras, Celia Caula, Francesc Collado-Roura, Ernest Castro, Margarida Casellas, Jorge Garcia-Adamez, and Antoni Codina-Cazador have no disclosures to declare.

Publisher's Note Springer Nature remains neutral with regard to jurisdictional claims in published maps and institutional affiliations.

Electronic supplementary material The online version of this article (https://doi.org/10.1245/s10434-020-09462-x) contains supplementary material, which is available to authorized users.

(C) Society of Surgical Oncology 2021

First Received: 29 July 2020

Accepted: 25 November 2020;

Published Online: 5 January 2021

S. López-Ben, MD

e-mail: santilb@msn.com 